\title{
AN ANALYSIS OF NON-STEADY PLASTIC SHOCK WAVES IN SNOW
}

\author{
By R. L. BROwn* \\ (Department of Civil Engineering and Engineering Mechanics, Montana State University, \\ Bozeman, Montana 597 I 7 , U.S.A.)
}

\begin{abstract}
The propagation of plastic shock waves in snow is analyzed in order to evaluate the effect of wave intensity and frequency content on attenuation. The results show that frequency content is not very significant and that large amplitude pressure waves lose their effectiveness very quickly. These results seem to support the present-day contention that air-induced explosions are a more effective means of controlling avalanches than explosives placed in the snow-pack and that explosive speed is not a particularly important factor in determining explosive effectiveness.

RÉsumé. Une analyse d'une onde de choc plastique instable dans la neige. La propagation d'une onde de choc plastique dans la neige est analysée pour évaluer l'effet de l'intensité de l'onde et de sa fréquence sur l'atténuation. Les résultats montrent que cette fréquence n'est pas très significative et qu'un grand nombre d'ondes de pression perdent leur efficacité très rapidement. Ces résultats semblent corrobororer les affirmations actuelles selon lesquelles les explosions dans l'air sont un meilleur moyen de déclenchement d'avalanche que les explosifs placés dans la neige et que la vitesse d'explosion n'est pas un facteur particulièrement important pour déterminer l'efficacité de l'explosion.

Zusammenfassung. Eine Analyse nicht-stetiger plastischer Schockwellen in Schnee. Die Fortpflanzung plastischer Schockwellen in Schnee wird untersucht, um die Wirkung der Wellenintensität und des Frequenzspektrums auf die Schwächung ermitteln zu können. Die Ergebnisse zeigen, dass das Frequenzspektrum keine grosse Bedeutung besitzt, und dass Druckwellen mit grosser Amplitude sehr schnell ihre Wirkung verlieren. Diese Ergebnisse scheinen die herrschende Ansicht zu stützen, dass Explosionen in der Luft ein wirksameres Mittel zur Auslösung von Lawinen sind als Sprengungen in der Schneedecke selbst, und dass die Explosionsgeschwindigkeit kein besonders wichtiger Faktor bei der Bestimmung der Explosionswirkung ist.
\end{abstract}

\section{INTRODUCTION}

Stress-wave propagation in snow is a problem which has not been studied as extensively as other areas of snow mechanics. Among those who have investigated shock waves are Napadensky (1964), Gubler (1977), Johnson (unpublished), Wakahama and Satō (1977), and Brown (1980). Napadensky's and Gubler's work was experimental, and Johnston restricted his work to elastic sonic waves. Brown (I980) made an analytical study of plastic pressure waves in snow but restricted himself to the mathematically simpler problem of steady waves. To date few investigators have studied the propagation of non-steady plastic shock waves in snow. This is not surprising, since prior to 1978 (Brown, 1979), there did not exist a volumetric constitutive law capable of characterizing the response of snow to large high-rate volumetric deformations. Without such a constitutive law, a detailed study of shock waves is not possible.

Brown ( 1980 ) utilized this volumetric constitutive law to investigate steady shock waves in which the wave-front profile, wave speed, and amplitude do not change as the wave propagates through a medium. These stress waves are idealistic, and even for plane waves such a condition can only be short-lived in a dissipative material such as snow. However, the steady wave assumption greatly simplifies the mathematics and does allow one to obtain good estimates of such parameters as shock-wave speed, density jump, and pressure jump. Attenuation of the wave amplitude and modification of the wavefront profile cannot be accurately determined, however, if the stress wave is assumed steady.

* This paper was prepared while the author was on sabbatical leave to U.S. Army Cold Regions Research and Engineering Laboratory, Hanover, New Hampshire 03755, U.S.A. 
The attenuation of pressure waves in snow is a topic which is relevant to the problem of avalanche initiation. Gubler (I977), who systematically studied the effectiveness of explosives for the artificial release of avalanches, compared the relative effectiveness of explosives placed above, on, and below the snow-pack surface. His results show that the least effective means of triggering avalanches is the method now commonly used - the practice of placing the charge below the snow-pack surface. Gubler attributed the main cause of this to the poor coupling between the snow and the explosion. Apparently the coupling between the snow and air is much better than between the explosion and snow, and a high percentage of the energy associated with an air pressure wave is transmitted to the snow-pack. However, since the study by Gubler (1977), this fact has been widely recognized by field personnel, and the practice of placing the explosive below the snow-pack surface is now beginning to disappear in Europe. In the United States, however, progress is much slower.

Another question which has not been resolved is the effect of frequency on the attenuation of pressure waves. Studies by Lang (1976) have shown that for very low-energy pulses, attenuation increases as frequency increases. The work by Lang has shown that acoustic emission pulses in the frequency range of $100000 \mathrm{~Hz}$ attenuate much more quickly than those in the audible range $\left(5^{0} \mathrm{~Hz}\right.$ to $\left.20000 \mathrm{~Hz}\right)$. However, whether or not the same result holds for plastic waves has not been determined.

Explosives which are used in avalanche control are often classified as either "fast" or "slow" according to their burning rate. The fast explosives have short rise times for the impulse, and consequently their impulse has a higher frequency spectrum than slow explosives. Fast explosives are generally used in avalanche control, but there is still some disagreement between avalanche experts over the optimum speed of explosives. LaChapelle (1977) has been studying alternate methods of avalanche initiation which involve the use of propane gas, which would produce a much slower explosion with a low-frequency content. To date, however, the relative effectiveness of slow and fast explosives has not been satisfactorily established, because the effect of frequency on the attenuation is not clearly understood.

In this paper we analyze the propagation of non-steady waves in snow. The equation of motion and the continuity equation are solved by making use of a volumetric constitutive law for snow. The resulting solution allows us to study in detail the attenuation of the pressure wave and the effect of frequency on propagation characteristics. In this way, some of the significant questions regarding the effect of detonation rates on snow can be answered.

\section{Analysis}

Under volumetric deformation, snow behaves as a non-linear rate-sensitive material. For pressures which produce inelastic yielding, this behavior may be represented by the following relationship (Brown, in press):

$$
p=\frac{2 \Upsilon_{0} f \exp \left(-\phi^{\alpha} / \alpha_{0}\right)}{3^{\alpha}} \ln \left[\frac{\alpha}{\alpha-1}\right]+\frac{\tau^{2} \Upsilon_{0}}{\alpha}\left[-\ddot{\alpha} f(\alpha)+\frac{(\dot{\alpha})^{2}}{6} g(\alpha)\right],
$$

where

$$
\begin{aligned}
\tau^{2} & =\rho_{\mathrm{m}} a_{0}^{2} /\left[{ }_{3} Y_{0}(\alpha-\mathrm{I})^{\frac{2}{3}}\right], \\
f & =(\alpha-\mathrm{I})^{-\frac{1}{3}}-\alpha^{-\frac{1}{3}}, \\
g & =(\alpha-\mathrm{I})^{-4 / 3}-\alpha^{-4 / 3},
\end{aligned}
$$

$\Upsilon_{0}, \mathcal{F}, \phi$ are all material constants, $a_{0}$ is the initial mean void radius, and $\rho_{\mathrm{m}}$ is the density of ice. The density ratio $\alpha$ is defined to be

$$
\alpha=\rho_{\mathrm{m}} / \rho,
$$

where $\rho$ is the mass density of snow, and $\alpha_{0}$ is the initial density ratio of snow. Equation (I) models snow as a non-linear viscoplastic material with a rate-sensitive yield stress. Brown 
( 1979,1980$)$ has described the volumetric response for a wide range of stress levels and rates of deformation, but for the case of plastic stress waves Equations (I)-(4) adequately describe the behaviour of snow.

The equation of motion and the continuity equation are, respectively, for a plane wave propagation in the $x$-direction

$$
\begin{aligned}
& \frac{\partial \sigma_{x}}{\partial X}+\rho_{0} b_{0}=\rho_{0} \frac{\partial v}{\partial t}, \\
& \frac{\rho_{0}}{\rho} \frac{\partial \rho}{\partial t}+\frac{\partial v}{\partial X}=0 .
\end{aligned}
$$

The coordinate $X$ is the undeformed position of a material particle. $\sigma_{x}$ is the normal stress, $b_{0}$ is the body force, $v$ is the particle velocity, and $\rho_{0}$ is the initial density. These two equations may be put in the following forms if body forces are neglected and if the stress state is primarily a hydrostatic pressure:

$$
-\frac{\partial \hat{p}}{\partial X}=\rho_{\mathrm{o}} \frac{\partial v}{\partial t}
$$

and

$$
\frac{\partial v}{\partial X}=\frac{\mathbf{I}}{\alpha_{0}} \frac{\partial \alpha}{\partial t}
$$

Differentiate Equation (9) once with respect to time and substitute Equation (8) to obtain

$$
-\frac{\mathrm{I}}{\rho_{0}} \frac{\partial^{2} \hat{p}}{\partial X^{2}}=\frac{\mathrm{I}}{\alpha_{0}} \frac{\partial^{2} \alpha}{\partial t^{2}} .
$$

This is a familiar form of the wave equation. Now substitute the constitutive equation (Equation (I)) into Equation (IO) to express the wave equation completely in terms of $\alpha$.

where

$$
E_{\mathrm{T}} \frac{\partial^{2} \alpha}{\partial X^{2}}+\frac{\partial E_{\mathrm{T}}}{\partial X} \frac{\partial \alpha}{\partial X}=\frac{\rho_{0}}{\alpha_{0}} \frac{\partial^{2} \alpha}{\partial t^{2}}+\frac{\partial}{\partial X}\left[E_{\mathrm{I}} \frac{\partial \ddot{\alpha}}{\partial X}+E_{2} \frac{\partial \ddot{\alpha}}{\partial X}\right],
$$

$$
\begin{aligned}
& E_{\mathrm{T}}=-\frac{\partial p}{\partial \alpha}(\alpha, \dot{\alpha}, \ddot{\alpha}), \\
& E_{\mathrm{I}}=\frac{\partial \hat{p}}{\partial \alpha}(\alpha, \dot{\alpha}, \ddot{\alpha}), \\
& E_{2}=\frac{\partial p}{\partial \ddot{\alpha}}(\alpha, \dot{\alpha}, \ddot{\alpha}) .
\end{aligned}
$$

$E_{\mathrm{T}}$ is the tangent modulus for the material, while $E_{\mathrm{I}}$ and $E_{2}$ are here called the rate and acceleration moduli. Explicit forms for $E_{\mathrm{T}}, E_{1}$, and $E_{2}$ can be found by substituting Equation (I) into Equations (I2), (13), and (I4). It can readily be seen that $E_{\mathrm{T}}, E_{\mathrm{I}}$, and $E_{2}$ are functions of $\alpha, \dot{\alpha}$, and $\ddot{\alpha}$, so that the resulting wave equation is a non-linear partial differential equation with variable coefficients. This equation is consequently quite difficult to solve analytically, and either a numerical solution or an approximate solution must be used.

In addition to the differential equation given above, the jump equations used by Brown (1980) can be applied to the case of non-steady waves. These equations, which respectively can be derived from the momentum and mass conservation principles, are

$$
\hat{p}=\frac{-\rho_{0} C_{0}^{2}}{\alpha_{0}}\left(\alpha-\alpha_{0}\right)
$$




$$
v=\frac{\hat{p}}{\rho_{0} C_{0}} .
$$

In the above $C_{0}$ is the wave speed, and $v$ is the particle velocity. These equations can be used to calculate wave speed and particle velocity behind the wave.

Equation (II) is solved numerically by a finite-difference technique to determine the spacial and temporal variation of $\alpha$ due to a shock wave. In particular consider the case of a snow-pack surface which is loaded by a pressure pulse of the form

$$
\hat{p}(0, t)=\frac{1}{2} P^{\star}(\mathrm{I}-\cos (w t)), \quad 0 \leqslant w t \leqslant 2 \pi .
$$

We calculate the response of a homogeneous snow-pack as the pressure pulse propagates into the material. The above simplified form for the surface loading allows us conveniently to make a parametric study of wave intensity and wave frequency, which are determined by $P^{\star}$ and $w$. Loadings due to actual explosives contain a frequency spectrum which could be approximated by a Fourier series representation of $\hat{p}(o, t)$, but the above simplified form allows us an easier means of studying the effect of $P^{\star}$ and $w$ on the wave propagation characteristics.

\section{Discussion OF RESUlts}

Figure I shows how the density change varies with time for a surface loading of i 2 bars and a dominant frequency, $\omega=w / 2 \pi$, of $5000 \mathrm{~Hz}$. Note here the rapid attenuation in the density change and the spreading of the wave front after only $5 \mathrm{~cm}$ into the snow-pack. The finite-difference solution does exhibit a "ring", or oscillatory variation in the density change. This is a familiar problem of finite-difference methods for highly transient phenomena, but in this case the ring quickly damps out and is not a severe problem. Figure 2 shows the densitychange profile over the first ten centimeters of depth for the same wave during the first two milliseconds of surface loading. This figure also demonstrates the spreading of the wavefront as the shock wave propagates into the snow-pack.

If one were to vary the wave intensity $P^{\star}$, the essential features shown in Figures $\mathrm{I}$ and 2 would be preserved, so Figures I and 2 are not repeated for different values of $P^{\star}$. Figure 3 , however, shows the density change for three different values of $P^{\star}$. Note that the relative advantage of the higher pressures are substantially eliminated in the first ten centimeters below the snow-pack surface, assuming other variables such as frequency, $\omega=w / 2 \pi$, remain constant. This points out the significant capability of snow to absorb and dissipate energy.

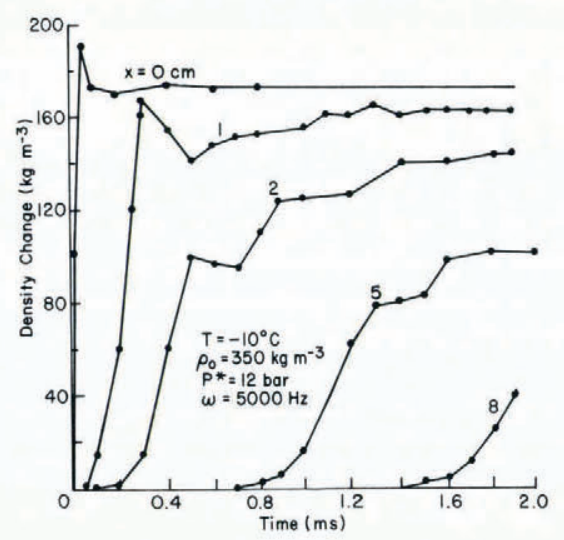

Fig. I. Variation of density change with time due to surface induced shock wave. 


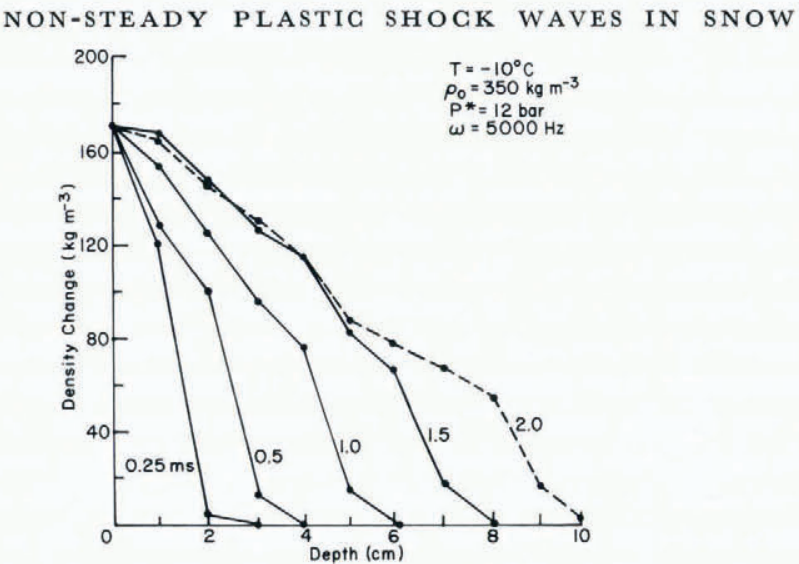

Fig. 2. Variation of density change profile with time in shock wave.

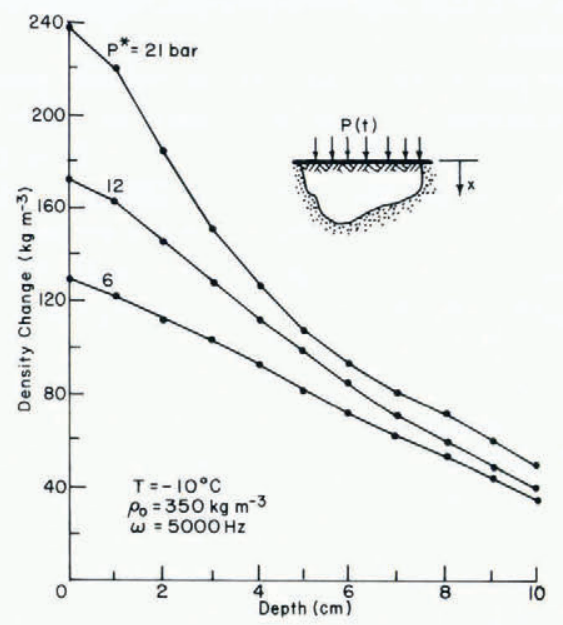

Fig. 3. Density change due to surface loading of snow-pack.

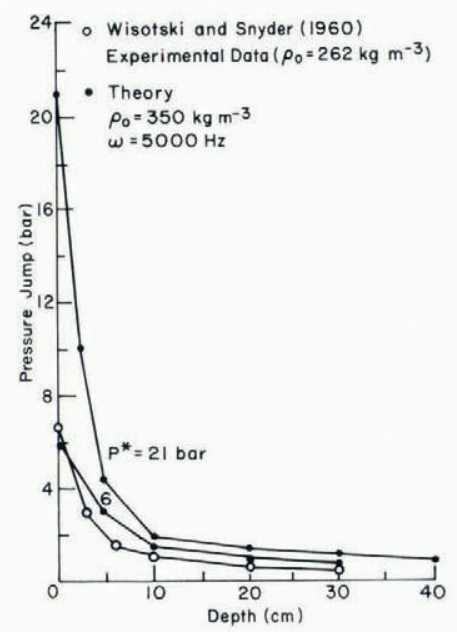

Fig. 4. Variation of peak pressure with distance from snow-pack surface. 
As the wave attenuates and spreads, the attenuation rate also decreases, as evidenced by Figure 3. Figure 4 shows the attenuation of the peak pressures for two of the cases considered in Figure 3. A sharp attenuation in peak pressure is also indicated. Generally the peak pressure occurs very close to the instant that the maximum density change occurs.

There is little experimental data with which the results of this study can be compared. Wisotski and Snyder (1966) however did conduct some field tests on the propagation of stress waves in snow. One pound $(0.45 \mathrm{~kg})$ of penolite spherical charges were placed at mid depth in a $50 \mathrm{~cm}$ deep seasonal snow-pack in the Colorado Rocky Mountains. Piezoelectric barium titanate transducers were placed in the snow at the same depth at distances of about 25 to $100 \mathrm{~cm}$ from the charge center. These transducers apparently had a good frequency response in the sonic range, but the problem of impedence matching was not discussed. The pressure variation recorded by Wisotski and Snyder is shown in Figure 4. The closest transducer recorded a peak pressure of 7.25 bar, and this was placed at the zero depth coordinate in Figure 4 for comparison with the 6 bar curve shown there. As can be seen, the comparison is acceptable. The snow density is about $270 \mathrm{~kg} \mathrm{~m}^{-3}$ which would in part account for the more rapid attenuation. The results of Wisotski and Snyder were adjusted to account for attenuation associated with geometric spreading.

Equations I 5 and 16 may be used to find the wave speed and particle velocity associated with the shock wave. Use of Equation 15 gives the variation of the shock-wave speed with distance below the snow-pack surface. The wave speed $C_{0}$ goes through a considerable variation as the wave propagates into the snow for two different surface pressures of 2 I and 6 bars shown in Figure 5. The waves for both pressures have slowed to their minimum speed within the first $10 \mathrm{~cm}$, and beyond this the wave speed can be expected to increase as the waves continue to attenuate while propagating further into the snow-pack. These results are in close agreement with the earlier results of Brown ( 1980 ) for steady waves. These pressure waves will eventually attenuate to the point where they become elastic waves, and at this point the wave speed should reach the value of the elastic wave speed. This occurs at velocities near $35^{0}-45^{\circ}$ $\mathrm{m} \mathrm{s}^{-1}$ for snow with an initial density of $350 \mathrm{~kg} \mathrm{~m}^{-3}$. The weaker shockwave in Figure 5 has already begun to experience an increasing wave speed within the first ten centimeters.

Wisotski and Snyder (I966) recorded arrival times in their field studies of shock waves in snow. However, there was too much scatter in the data, and it was not possible to obtain an accurate estimate of the wave speed in the plastic zone around the charge.

The effect of explosive speed on the propagation of a pressure wave can also be investigated by varying $w$ in Equation ( 17 ) to represent the speed of the explosive-induced surface loading. In Figure 6 the attenuation characteristics for values of $\omega=w / 2 \pi$ of $5 \mathrm{kHz}, 50 \mathrm{kHz}$, and

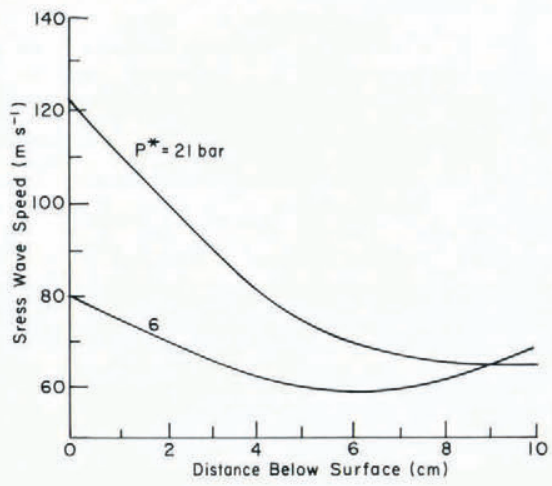

Fig. 5. Variation of shock-wave speed with distance below surface. 
I $50 \mathrm{kHz}$ are shown. The lower-frequency wave experiences less attenuation than the other two waves, but due to the rapid spreading of the waves, this difference becomes less significant with increasing distance into the snow-pack. Figure 6 would appear to imply that for the range of frequencies considered here, there does not appear to be much advantage of one speed of explosive over another for the case of plastic waves. This result should not be construed to imply the same for elastic waves.

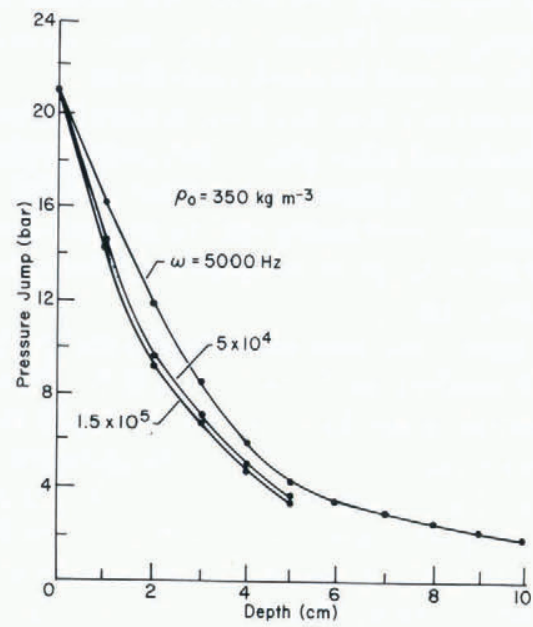

Fig. 6. Effect of explosive speed on attenuation of shock waves.

Only pressure waves producing volumetric deformations of the snow-pack were considered in this study. This was done since the constitutive law used in this study does not include deviatoric deformations. Since snow is capable of dissipating large amounts of energy through irreversible volumetric strains, it is felt that this type of wave is responsible for a significant portion of the energy dissipation associated with stress waves. However, one may legitimately question whether hydrostatic or deviatoric stresses are more effective for disturbing the snow cover to release an avalanche. For example, a snow slope with a basal layer of depth hoar may avalanche when this layer collapses due to the effects of a stress wave. It is possible that this depth-hoar layer could collapse downward under compaction, or it could fail under a shearing deformation. Presently, the predominant mode of failure is not known. However, both types of failure can be caused by a pressure wave, since a pressure wave which strikes a surface such as the ground can reflect both shear and pressure waves. As a consequence pressure waves could be relevant to avalanches, regardless of the manner in which failure takes place.

It should also be noted that this study was concerned with the pressure wave associated with the compaction of the snow due to plastic deformation of the solid phase. Energy may also be transported through the snow by an airwave which propagates through the pores which have a high degree of interconnectivity. This type of wave may be able to propagate with less rapid attenuation. More work needs to be done to investigate this possibility.

\section{Conclusions and Regommendations}

The results presented here have shown some interesting and significant facts concerning the propagation of plastic shock waves in snow. First, these results appear to support Gubler's (1977) contention that air-induced blasts are more effective than explosives placed in the 
snow-pack. Aside from considering such factors as geometric spreading and poor coupling between the explosive and snow, the results show that the pressure wave is severely attenuated within a very short distance from ground zero where the explosive is discharged. The airwave associated with an air explosion would arrive at the snow surface above this point with much less attenuation than if it had propagated in the snow. Also, the distance the wave must propagate into the snow-pack from the air would generally be no more than a meter perpendicular to the slope since many snow-pack depths do not exceed one meter. Taking this into account, it is not at all surprising that Gubler (1976) saw an order of magnitude difference between pressures generated by air and in-snow explosives.

In this study, only the response of snow to plastic waves is considered, since this is where a good portion of the energy adsorbtion takes place. Beyond the distance of $10 \mathrm{~cm}$ shown in the figures, attenuation rates in waves continue to decrease, until it becomes negligible in comparison to effects such as geometric spreading and boundary interaction. However, as long as the wave amplitude is sufficient to produce plastic deformation in the snow, attenuation rates in snow will exceed those in air.

The results of this study point out two important results which should be investigated experimentally. These are illustrated in Figures 4 and 6. First, the advantage of a highpressure pulse over lower pressures is quickly reduced, as shown in Figure 4. This result might. indicate that an explosive producing a lower maximum pressure may not be significantly less effective but much more economical. This does not necessarily imply the same result regarding explosive size. Figure 6 indicates that there really is not much difference between fast and slow explosives. The speed here is reflected in the dominant frequency of the pressure pulse.

The results of this study and the study by Gubler (1977) point out the need for the development of an air-detonated explosive to initiate avalanches. A system similar to the SLUFAE (Surface Launched Unit Fuel Air Explosive) now operational in the U.S. Army might be very effective for such purposes, although a scaled-down system suitable for the $105 \mathrm{~mm}$ Howitzers would have to be developed. Upon impact a combustible fluid is dispersed into the air, and the cloud is then ignited to produce overburden pressures of 20 bar directly to the snow-pack surface. There are some problems such as cost, effectiveness in storms, and fire hazard, which would have to be solved, but the obvious advantages of such an air exploded system are encouraging. The present method of discharging the explosive in the snow is less than $20 \%$ effective, which in itself makes this method expensive and inefficient.

\section{Agknowledgement}

The work reported here was supported by U.S. Army under ARO Research Grant No. DRXRO-PR P-I54I3-GS. The author would like to express his appreciation for support from the Army Research Office and the U.S. Army Cold Regions Research and Engineering Laboratory.

MS. received 28 March 1979 and in revised form 9 May 1979

\section{REFERENCES}

Brown, R. L. 1979. A volumetric constitutive law for snow subjected to large strains and strain rates. U.S. Cold Regions Research and Engineering Laboratory. Report 79-20.

Brown, R. L. I980. Pressure waves in snow. Fournal of Glaciology, Vol. 25, No. 91, p. 99-107.

Grown, R. L. 198. Artificial release of avalanches by explosives. Fournal of Glaciology, Vol. 19, No. 81, p. 419-29.

Johnson, J. B. Unpublished. Stress waves in snow. [Ph.D. thesis, University of Washington, Seattle, Washington, 1978.] 
LaChapelle, E. R. r 977 . Alternate methods for the artificial release of snow avalanches. Fournal of Glaciology,
Vol. i9, No. 8i, p. $389-97$. Lang, T. E. 1976. Measurements of acoustic properties of hard-pack snow. Journal of Glaciology, Vol. 1 7, No. 76,
p. $269-76$. Napadensky, H. 1964 . Dynamic response of snow to high rates of loading. U.S. Cold Regions Research and Engineering
Laboratory. Research Report 119 .

Wakahama, G., and Satō, A. 1977. Propagation of a plastic wave in snow. Fournal of Glaciology, Vol. I9, No. 8I, p. I 75-83.

Wisotski, J., and Snyder, W. 1966. A study of the effects of snow cover on high explosive blast parameters. University of Denver. Denver Research Institute. Report 2303. 